\title{
Clinical Studies of Dental Cements: I. Five Zinc Oxide-Eugenol Cements
}

\author{
T. D. GILSON and G. E. MYERS \\ School of Dentistry, University of Michigan, Ann Arbor, Michigan
}

Five zinc oxide-eugenol cements of varying compressive strengths, similar in other qualities, were used in a blind clinical study of luting temporary restorations. On the basis of retention, ease of removal when required, and ease of cleaning the restoration, two of the cements were found to serve best.

Zinc oxide-eugenol cements have long been used to cement temporary restorations in teeth prepared for inlays, crowns, or fixed bridges, ${ }^{1,2}$ and a variety of products is available to the dentist. During the last 25 years, the physical properties of these materials have been studied, and numerous improvements in physical characteristics and manipulative qualities have been achieved..$^{3-17}$ Little information has been available, however, on the clinical behavior of the zinc oxideeugenol cements. No data have been collected that correlate physical properties with the clinical behavior of these cements in the oral environment, and the clinician has relied on his own judgment in the selection of a cement for a particular instance. It has come to be recognized that the compressive strength of a cement has a relationship to its ability to hold a restoration in place; the stronger the cement, the more securely the restoration is retained. For temporary crowns, a cement is required that has sufficient strength to hold a variety of restorations in place but that is not so strong as to make removal of the restoration difficult. This study was an attempt to find the optimum strength for a cement for luting temporary restorations.

Clinical evaluation presents difficulties in controlling all the factors involved, the retention quality of the preparation, the adap-

This investigation was supported in part by Project No. 07174 from the Board of Regents, University of Michigan, and the L. D. Caulk Company, Milford, Del.

Received for publication February 5, 1968. tation of the temporary restoration, individual manipulative variations of the operator, variation in occlusal relationships and occlusal forces, and many others. A clinical evaluation of this type is not directed to securing basic information of the physical properties of the cements, but rather to collecting information on how cements behave in a full range of applications in practice. By collecting data from a large sample under controlled conditions and using criteria as specific as possible, a more effective evaluation can be obtained than in the wider and less controlled field test of releasing the materials for general use in practice. The type of study here described can well precede the field test, which at present remains the ultimate long-term testing method for restorative materials.

In addition to studying the retentive qualities of the cements and the ease of removal of the restorations, other factors that were recorded and evaluated were taste, handling qualities, and ease of cleaning the restoration for reuse.

\section{Materials and Methods}

Five experimental zinc oxide-eugenol cements were available for clinical evaluation. The compressive strengths were: cement $\mathrm{A}$, 1,000 psi; cement B, 200 psi; cement C, 2,200 psi; cement D, 5,400 psi; and cement E, 3,500 psi. The cements met these criteria: (1) easily mixed in 60 seconds; (2) creamy consistency and no tendency to drip from restorations when inserted; and (3) working time not less than 3.0 minutes and not more than 5.5 minutes. The physical properties of the cements were unknown to the investigator and the operator.

The cements were allocated routinely, using a random distribution technic, for cementing all types of temporary restorations. Measured quantities of base and cata- 
lyst were supplied for each application. These quantities were uniform for each cement.

Each cement was mixed by spatulation on a parchment paper in the minimum time required to achieve a homogenous mix. In all instances, spatulation was completed in 30 to 45 seconds.

At the time the temporary restoration was cemented in place, a series of questions was posed to the operator and the answers were recorded on the data sheet. The questions were worded to determine whether the mixing of the cement was easy, whether the working time was adequate, whether excess cement could be removed easily, whether the restoration could be seated readily, and whether the patient made any unsolicited comment about a burning taste.

When the temporary restoration was removed, information was similarly collected regarding whether the restoration had remained firmly in position, whether removal was easily done, whether the dentin surface was readily cleaned, whether the restoration could be easily cleaned for reuse if required, and whether (with acrylic restorations) any color change was noticeable.

In determining the ease with which a restoration was removed, provision was made for three categories: easy removal (with normal hand pressure and hand instruments or with light taps from a mallet), difficult removal (with unusual hand pressure or by repeated application of force with a mallet), and impossible removal (only by cutting or other mutilation).

In determining the facility with which the dentin surface could be freed from cement, two possible categories were recognized: easy removal (cement could be wiped away with a cotton pledget) and difficult removal (hand instruments were required to remove the cement). The criteria for determining the facility of cleansing the cement from the restoration for reuse were: easy removal (cleaned in a few minutes with hand instruments), difficult removal (considerable time required to clean the restoration with hand instruments), and impossible removal (destruction of the restoration necessary).

During the 75-day collection period, 320 data sheets that involved 610 , restorations in approximately 120 patients were summarized in complete tabular form. The rela- tive information was selected and graphs were constructed.

\section{Results}

General handling Qualities.-The general handling qualities were satisfactory in all the cements. The mixed cements had a creamy, homogeneous consistency and did not drip from the restorations during placement. All cements allowed sufficient working time. There was no difficulty in seating restorations in the mouth and little or no difference among the cements regarding ease of removal of excess cement. No cement caused any detectable color changes in acrylic restorations. All the cements could be easily removed from the tooth.

RETENTIVE QUALITIES.--The data on the retentive qualities of the cements for all types of temporary restorations are summarized (Fig 1). Restoration types included are aluminum crown forms, acrylic inlays, and crowns as single restorations and acrylic bridges.

The five cements were in two groups insofar as their retentive characteristics were concerned. Cements $C, D$, and $E$ were in one group, and cements $\mathrm{A}$ and $\mathrm{B}$ were in the other group. The latter cements had a failure rate about twice that of the first group. This difference was readily noticed clinically; many restorations cemented with cements A and B came loose shortly after placement. These two preparations were withdrawn during the last weeks of the study.

The analyses of the data regarding aluminum crowns on single restorations (Fig 2)

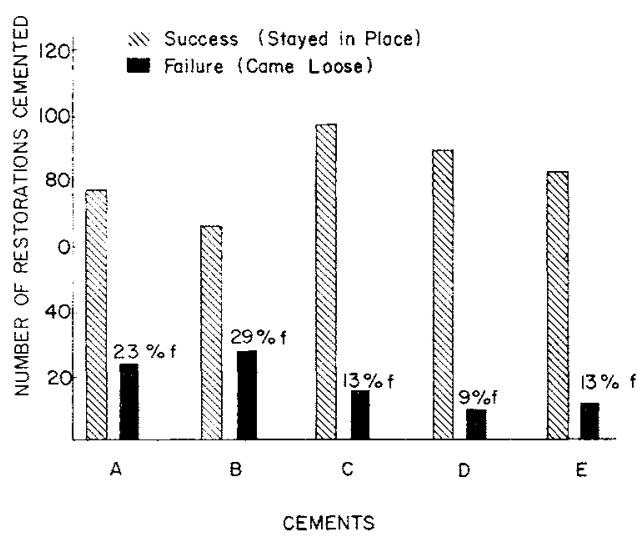

FIG 1.-Retention data for all temporary restorations. 


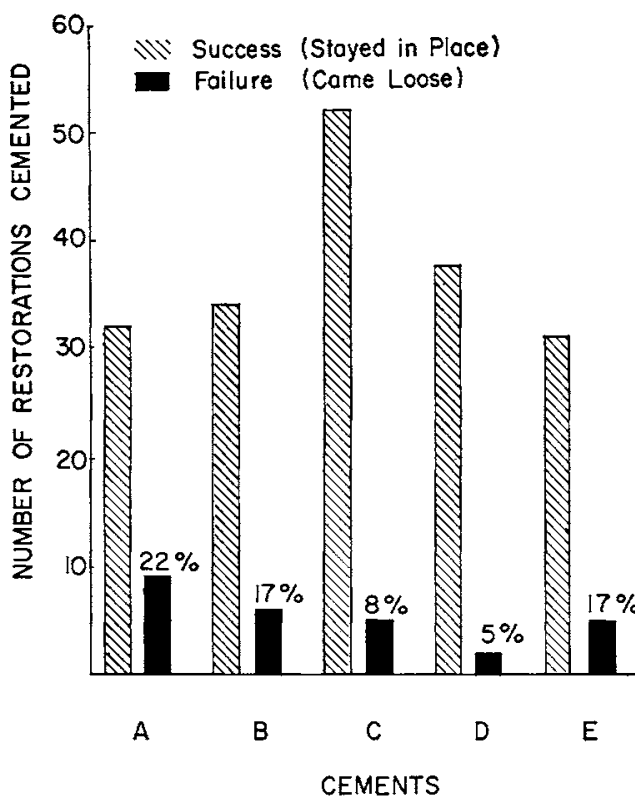

FIG 2.-Retention data for aluminum crown forms.

and acrylic inlays and crowns (Fig 3) are shown graphically. In general, the cements were more successful than acrylic inlays or crowns in retaining aluminum crown forms, as seen in the generally lower failure percentages. Cement $D$, which had the highest in compressive strength, had the lowest failure rate in the aluminum crown series but had a higher failure rate than cement $\mathrm{C}$ and $\mathrm{E}$ in the acrylic inlay and crown series.

TASTE.-An analysis of the data on taste (Fig 4) indicated that there were two groups, similar to those for retentive qualities. Cements $A$ and $B$ caused the least burning, and cements $\mathrm{C}, \mathrm{D}$, and $\mathrm{E}$ caused a greater incidence of burning.

REMOVAL OF THE RESTORATION.-The data regarding the ease of removal of temporary restorations are shown (Fig 5). In most restorations cemented with $\mathrm{A}$ and $\mathrm{B}$, there was no difficulty at the time of removal of the restoration. With cements $C, D$, and $\mathrm{E}$, there was a higher proportion of problems. Cement D gave the highest incidence of removal problems and was the only cement categorized under "impossible removal."

Cleaning the Restoration for ReUSE,The relative ease in cleaning the restoration for reuse is indicated (Fig 6). The same two

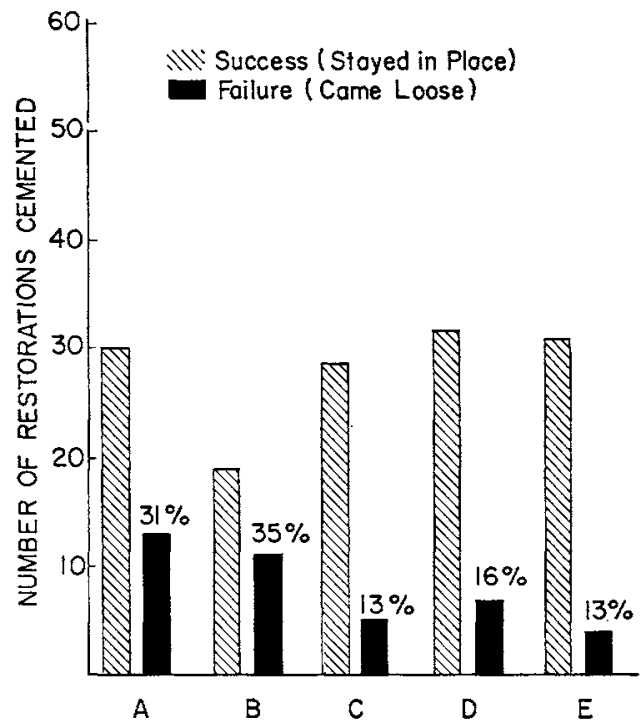

FIG 3.- Retention data for acrylic inlays and crowns.

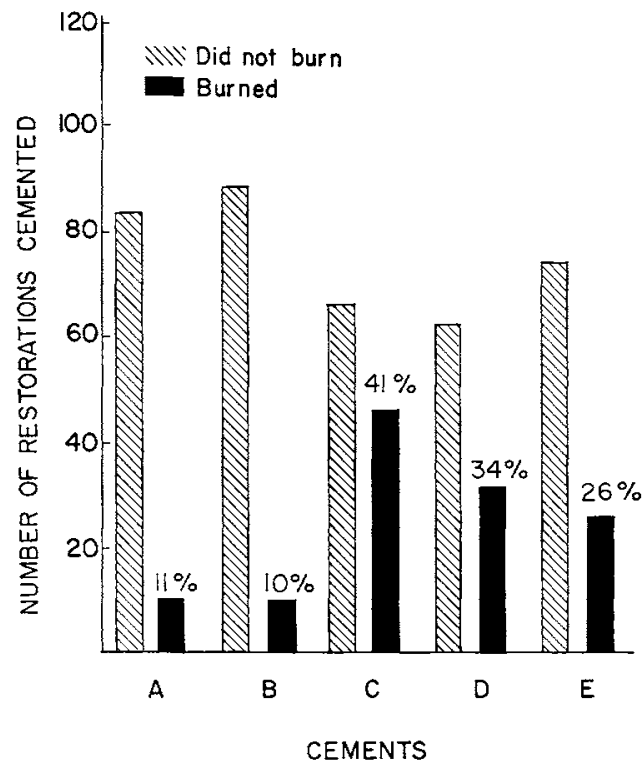

FIg 4.-Data regarding taste for all restorations.

groups can be recognized, with cements $A$ and $\mathrm{B}$ being easily cleaned from the restoration in a high percentage of instances. Cement $D$ caused the highest incidence of problems. 


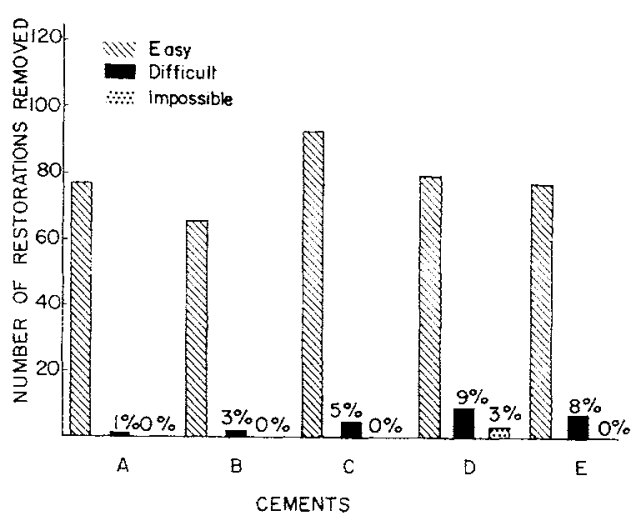

FIG 5.-Data collected at the time of removal of restorations, regarding ease of removal.

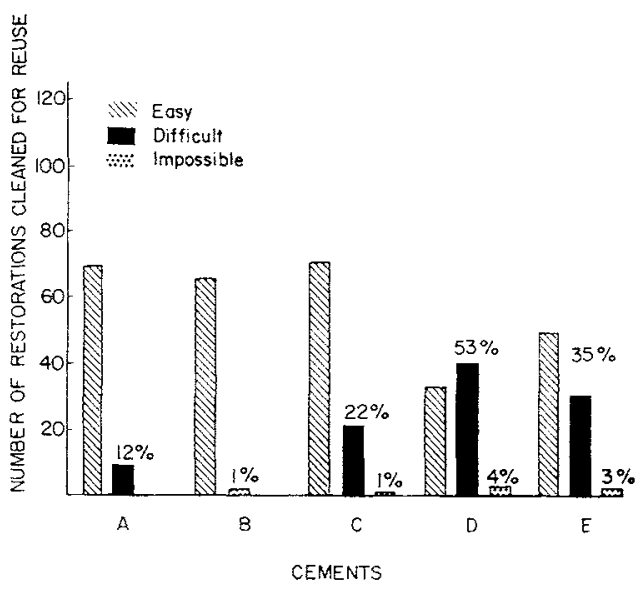

FIG 6.-Data collected at the time of removal of restorations, regarding ease of cleaning for reuse.

\section{Discussion}

The main factors for selection of the most suitable cement are retention and ease of removal when required. Cements $\mathrm{A}$ and $\mathrm{B}$ can be excluded because of the high failure rate in retention and because of the creation of clinical situations that became inconvenient for both operators and patients. Concerning retention, cement $\mathrm{D}$ was the most satisfactory, but problems at the time of removal were more frequent than the average operator would like to meet in daily practice. Cements $\mathrm{C}$ and $\mathrm{E}$ appear equally satisfactory in retention and ease of removal. The data collected in this study were not of sufficient quantity to allow any statistical comparison of these two cements.

The clinically noticeable failure rate of cement $\mathrm{D}$ with acrylic inlays and crowns is interesting, considering its behavior with aluminum crown forms, with which it was the most successful. In most instances, the acrylic restoration came loose from the cement, which still adhered to the tooth in many areas. Cement $\mathrm{D}$ is very hard when set, and it is thought that the resiliency of the acrylic in relation to the unyielding nature of the cement concentrated stresses at the interface and caused early separation of the restoration from the cement. This phenomenon occurred especially often with thin restorations; eg, anterior three-quartercrown temporary restorations.

The burning sensations recorded were not severe and were of the nature commonly found with this type of cement.

Difficulty in cleaning the cement from the restoration after removal from the tooth was related to the strength of the cement, the strongest cement creating the greatest difficulties and the weakest cement being easy to remove. The strongest preparation was considered unsuitable as a temporary cement.

\section{Conclusions}

The retentive quality of a cement for luting temporary restorations varied directly with its compressive strength, except with acrylic restorations.

Of the five cements studied, the two cements with compressive strengths of 2,200 and 3,500 psi, respectively, most nearly met the requirements of a cement for luting temporary restorations.

\section{References}

1. Segat, L.: Protection of Prepared Abutments Between Appointments, Mich Dent Assoc J 44:32-39, 1962.

2. Berglers, G.K.: Procedure for Temporary Replacement in Crown and Bridge, Dent Dig 69:120-123, 1963.

3. Molnar, E.J., and Skinner, E.W.: A Study of Zinc Oxide-Eugenol Cements: I. Some Variables which Effect Hardening Time, J Amer Dent Assoc 29:744-751, 1942.

4. Harvey, W., and Petch, N.J.: Acceleration of the Setting Time of Zinc OxideEugenol Cements, Brit Dent J 80:1-8, 1946.

5. Harvey, W., and PeTch, N.J.: Acceleration of the Setting Time of Zinc Oxide- 
Eugenol Cements, Brit Dent J 80:35-42, 1946.

6. Massler, M., and Ostrovsky, A.: Sealing Qualities of Various Filling Materials, J Dent Child 21:228-234, 1954.

7. Copeland, H.I., Jr.; Brauer, G.M.; SWEeney, W.T.; and Forziati, A.F.: Setting Reaction of Zinc Oxide-Eugenol, $J$ Res Nat Bur Sci 55:133-138, 1955.

8. Smith, D.C.: The Setting of Zinc OxideEugenol Mixtures, Brit Dent J 313-321, 1958.

9. WeIss, M.B.: Improved Zinc Oxide-Eugenol Cement, Illinois Dent $J$ 27:261-271, 1958.

10. Brauer, G.M.; White, E.E.; and Moshonas, M.G.: The Reaction of Oxides with O-ethoxybenzoic Acid and Other Chelating Agents, J Dent Res 57:547-560, 1958.

11. Norman, R.D.; Schwartz, M.L.; and PHILlips, R.W.: Additional Studies on the Solubility of Certain Dental Materials, $J$ Dent Res 38:1028-1037, 1959.

12. Messing, J.J.: A Polystyrene-Fortified Zinc
Oxide-Eugenol Cement, Brit Dent $J$ 110: 95-100, 1961.

13. HoRN, H.: Improved Cementation, $J$ Amer Dent Assoc 63:812-820, 1961.

14. Phillips, R.W., and Love, D.: The Effect of Certain Additives on the Physical Properties of Zinc Oxide-Eugenol Mixtures, $J$ Dent Res 40:294-303, 1961.

15. Norman, R.D.; Schwartz, M.L.; and PhIllips, R.W.: Studies of Film Thickness, Solubility and Marginal Leakage of Dental Cements, J Dent Res 42:950-958, 1963.

16. Schwartz, M.L.; Phillips, R.W.; Norman, R.D.; and OldhaM, D.F.: Strength, Hardness and Abrasion Resistance of Dental Cements, J Amer Dent Assoc 67:367-374, 1963.

17. Oldham, D.F.; Schwartz, M.L.; and PhilIPS, R.W.: Retentive Properties of Dental Cements, J Prosth Dent 14:760-768, 1964.

18. ANderson, J.R., JR., and MYers, G.E.: Physical Properties of Some Zinc OxideEugenol Cements, J Dent Res 45:379-386, 1966. 